\title{
Práticas Educativas Maternas e Problemas de Comportamento em Pré-Escolares
}

\author{
Patricia Alvarenga ${ }^{123}$ \\ Cesar Piccinini \\ Universidade Federal do Rio Grande do Sul
}

\begin{abstract}
Resumo
O presente estudo investigou as diferenças entre as práticas educativas relatadas por mães de crianças com e sem problemas de comportamento envolvendo externalização (grupo clínico e grupo não-clínico, respectivamente). Participaram do estudo 30 díades mãe-criança, de nível sócio-econômico baixo e médio-baixo. As crianças eram de ambos os sexos e tinham entre cinco e seis anos de idade. As díades foram designadas aos grupos clínico e não-clínico com base na pontuação da criança no Inventário de Comportamentos da Infância e Adolescência - CBCL. As mães responderam a uma entrevista sobre práticas educativas envolvendo situações estruturadas e espontâneas. Análise de conteúdo das entrevistas, relacionada às situações estruturadas, mostrou que as mães do grupo clínico mencionaram práticas coercitivas com uma freqüência significativamente maior do que as mães do grupo não-clínico. A mesma tendência, embora não significativa, apareceu para as situações espontâneas.

Palavras-chave: Práticas educativas; problemas de comportamento; pré-escolares.
\end{abstract}

\section{Childrearing Practices and Behavior Problems in Preschool Children}

\begin{abstract}
The aim of the present study was to investigate differences in mothers' childrearing practices toward children with and without behavior problems involving externalizing behaviors (clinical and non-clinical group, respectively). Thirty mother-child dyads from both low and medium-low SES level participated in the study. Children were of both sexes, with ages ranging from five to six years. The dyads were assigned to the clinical or non-clinical group based on the children's scores on the Child Behavior Checklist (CBCL). The mothers were interviewed about their childrearing practices in both structured and spontaneous situations. Content analysis of the interviews regarding the structured situations revealed that the mothers of the clinical group mentioned significantly more coercive practices than did mothers of the non-clinical group. The same trend appeared in the spontaneous situations, although the differences were not significant.

Keywords: Childrearing practices; behavior problems; preschool children.
\end{abstract}

As práticas educativas parentais têm sido objeto de estudo de inúmeras investigações nas últimas décadas. Muitas dessas pesquisas abordaram as possíveis implicações das práticas educativas utilizadas pelos pais no desenvolvimento de seus filhos. Entre outros fatores ligados ao desenvolvimento infantil, os problemas de comportamento têm sido enfatizados como uma das variáveis relacionadas às práticas educativas parentais.

\footnotetext{
${ }^{1}$ Endereço para correspondência: Instituto de Psicologia, Universidade Federal do Rio Grande do Sul, Rua Ramiro Barcelos, 2600, 90035-003, Porto Alegre, RS. Fone: (51) 33165066, Fax: (51) 33309507. E-mail: p.alvarenga@bol.com.br

${ }^{2}$ Este estudo foi baseado na Dissertação de Mestrado da primeira autora, realizada sob a supervisão do segundo autor, apresentada no Programa de Pós-Graduação em Psicologia do Desenvolvimento da UFRGS, Porto Alegre, RS.

${ }^{3}$ Os autores agradecem a colaboração de Luciana Anselmi e Fernando Barros, na fase de coleta dos dados, de Alexandre Baldasso Schossler, Luiz Otavio Staudt e Alziro dos Santos, durante a análise dos dados, bem como ao CNPq pelo auxílio financeiro.
}

No convívio diário, os pais procuram direcionar o comportamento dos filhos no sentido de seguir certos princípios morais e adquirir uma ampla gama de comportamentos que garantam independência, autonomia e responsabilidade, para que mais tarde possam desempenhar adequadamente seu papel social. Por outro lado, também esforçam-se para suprimir ou reduzir comportamentos que sejam considerados socialmente inadequados ou desfavoráveis. Para cumprir o papel de agentes de socialização dos filhos, os pais utilizam-se de diversas estratégias e técnicas para orientar seus comportamentos. Essas estratégias de socialização utilizadas pelos pais, são denominadas por alguns autores de práticas educativas parentais (Grusec \& Lytton, 1988; Mussen, Conger, Kagan \& Huston, 1990; Newcombe, 1996/1999).

A introdução da disciplina na vida da criança envolve um contexto de interação entre pais e filhos em que a criança começa a ser confrontada com as regras e padrões morais da sociedade através das práticas educativas 
parentais (Hoffman, 1975, 1994). O conjunto de estratégias disciplinares utilizadas pelos pais pode ser dividido em duas categorias distintas: as estratégias indutivas e as estratégias de força coercitiva. Ambos os tipos de estratégias têm por função comunicar à criança o desejo dos pais de que ela modifique seu comportamento, bem como pressionar a criança a obedecer.

Para (Hoffman, 1975, 1994) a estratégia indutiva caracteriza-se por atingir o objetivo disciplinar indicando para a criança as conseqüências do seu comportamento para as outras pessoas e chamando sua atenção para os aspectos lógicos da situação. Isso propicia à criança a compreensão das implicações de suas ações e, portanto, dos motivos que justificam a necessidade de mudança no seu comportamento. Desta forma, a criança desenvolve certa autonomia para utilizar esse tipo de informação para controlar seu próprio comportamento. Como exemplos desse tipo de estratégia pode-se citar o uso de explicações sobre o comportamento da criança e as suas conseqüências, explicações a respeito de regras, princípios e valores, apelos ao orgulho da criança, apelos baseados no amor que a criança sente pela mãe, e explicações sobre as possíveis implicações ruins ou dolorosas das ações da criança sobre os outros e sobre o seu relacionamento com as outras pessoas. Esse tipo de estratégia tende a facilitar a internalização de padrões morais (Hart, Ladd \& Burleson, 1990; Hoffman, 1991, 1994).

Já as estratégias de força coercitiva caracterizam-se, segundo Hoffman (1975), pela aplicação direta da força, incluindo punição física, privação de privilégios e afeto, ou pelo uso de ameaças dessas atitudes. Essas técnicas fazem com que a criança controle seu comportamento em função das reações punitivas dos pais. Além disso, elas produzem emoções intensas, tais como medo, raiva e ansiedade, que tendem a reduzir ainda mais a possibilidade de a criança compreender a situação e a necessidade de modificação de comportamento. Ou seja, o controle do comportamento da criança tenderá a depender de intervenções externas porque ela não adquire a capacidade de compreender as implicações de suas ações. Nesse sentido, as estratégias de força coercitiva não favorecem a internalização das regras sociais e padrões morais.

Além de não contribuir para a aquisição de padrões adequados de comportamento, o uso freqüente de estratégias coercitivas tende a fazer com que crianças comportem-se de forma coercitiva com seus pares. Hart e cols. (1990) investigaram se as expectativas de crianças a respeito dos resultados da utilização de estratégias amigáveis e não amigáveis para a resolução de conflito com os pares, relacionavam-se em alguma medida com as estratégias disciplinares maternas. Os dados confirmaram a hipótese dos autores de que ao utilizarem estratégias de força coercitiva os pais poderiam inadvertidamente modelar nos filhos o uso desse tipo de estratégia como um meio eficaz de resolver questões interpessoais.

O uso de práticas coercitivas pode ainda estimular e agravar um padrão inadequado de comportamento quando este padrão é ao mesmo tempo punido e reforçado (Catania, 1999). O comportamento de crianças que costumam provocar os pais até serem punidas pode ser explicado pelo fato de que as punições (surras ou castigos) são geralmente seguidas pela atenção dos pais arrependidos. Para Catania, a atenção dos pais pode ser um reforçador poderoso, especialmente se em outras circunstâncias a criança não tem acesso a ela. Nesse caso, o efeito reforçador da atenção dos pais superaria o efeito de supressão do comportamento inadequado induzido pela punição, o que explicaria a prevalência e o agravamento daquele padrão comportamental.

$\mathrm{Na}$ verdade, as estratégias disciplinares coercitivas, de um modo geral, tendem a cumprir apenas objetivos de socialização de curto prazo, fazendo com que a criança momentaneamente pare de se comportar de determinada forma ou forçando sua obediência (Sidman, 1989/1995; Skinner, 1954/1994). Talvez a eficácia dessas estratégias a curto prazo explique o fato de serem empregadas pela maioria dos pais em várias situações. No estudo de Grusec e Kuczynski (1980) em que foram realizadas entrevistas utilizando situações hipotéticas envolvendo situações de desobediência de crianças, foi encontrado que a maioria das mães usaria a privação de privilégios, sendo que setenta por cento delas disseram que bateriam e gritariam com a criança em algumas situações. Os achados apontaram para a importância das estratégias punitivas ou de força coercitiva no repertório de comportamento dos pais.

$\mathrm{Na}$ verdade, o uso ocasional de estratégias coercitivas não é necessariamente desfavorável para o processo de socialização (Newcombe, 1996/1999). Segundo Grusec e Lytton (1988) inicialmente as pesquisas apontavam para os efeitos danosos da coerção e, em função disso, seu uso era desaconselhado. Posteriormente outras pesquisas sugeriram que esses efeitos negativos ocorreriam especialmente com a utilização muito freqüente desse tipo de estratégia, com o uso de punições severas ou quando a punição fosse associada a manifestações de rejeição, mas não necessariamente quando usada moderadamente.

Contudo, relações entre práticas de caráter coercitivo e problemas de comportamento têm sido freqüente- 
mente reportadas na literatura. Dentre os diferentes tipos de problemas de comportamento, os de externalização (Achenbach, 1991), que correspondem ao comportamento agressivo, hiperatividade, desobediência e comportamento delinqüente, parecem estar especialmente relacionados às práticas coercitivas. Por exemplo, crianças freqüentemente expostas a estratégias disciplinares punitivas, tendem a demonstrar maior número de comportamentos agressivos e tentativas de transgredir normas, do que crianças pouco expostas a esse tipo de prática, cujos pais se utilizam de explicações e ordens simples para regular sua conduta (Trickett \& Kuczynski, 1986). Apoiando esses achados, o estudo de Pettit e Bates (1989) indicou que o afeto somado a uma atitude educativa e positiva da mãe, estaria, consistentemente, relacionado à ausência de problemas de comportamento, enquanto que as estratégias coercitivas e a ausência de um envolvimento positivo da mãe foram preditores de problemas de comportamento na infância. Fox, Platz e Bentley (1995) obtiveram resultados semelhantes num estudo com crianças pré-escolares. Mais precisamente, revelaram uma correlação positiva significativa entre o uso de punições físicas e a presença de problemas de comportamento, assim como uma correlação negativa entre práticas educativas não coercitivas e problemas de comportamento.

Relações similares foram encontradas em outros estudos (Dodge, Pettit \& Bates, 1994; Pettit, Bates \& Dodge, 1997; Rothbaum \& Weisz, 1994) nos quais o uso de estratégias disciplinares severas pelos pais, incluindo o uso de punições físicas apareceu significativamente associado com problemas de externalização das crianças.

O uso excessivo de punição e a ausência de afeto e de supervisão materna também têm sido apontados como preditores de delinqüência e criminalidade em adultos do sexo masculino (Loeber \& Dishion, 1983, citados por Grusec \& Lytton, 1988). Resultados semelhantes foram obtidos por Hart, Nelson, Robinson, Olsen e McNeillyChoque (1998), mostrando que a coerção parental e a falta de responsividade estavam significativamente correlacionadas com a agressividade dos filhos em relação aos pares. Patterson e Stouthamer-Loeber (1984) constataram ainda uma relação entre o tipo de manejo dos pais e a delinqüência entre crianças e adolescentes. A falta de supervisão dos pais desempenhou um papel central na presença e freqüência de comportamento delinqüente dos filhos.

Diferenças culturais também têm sido investigadas como um importante moderador do efeito das práticas educativas sobre o comportamento infantil. Problemas de externalização foram particularmente associados ao

Psicologia: Reflexão e Crítica, 2001, 14(3), pp. 449-460 uso de punições físicas em crianças americanas de origem européia, mas não em crianças afro-americanas (DeaterDeckard, Bates, Dodge \& Pettit, 1996). No estudo de Chen, Rubin, Cen, Hastings, Chen e Stewart (1998) a inibição comportamental, observada por exemplo, na falta de engajamento em brincadeiras com pares desconhecidos e na manutenção da proximidade da mãe em situações novas, esteve positivamente associada com estratégias punitivas maternas e negativamente com a aceitação e o encorajamento materno em uma amostra canadense. Já na amostra de crianças chinesas a direção das relações foi oposta: a inibição comportamental das crianças esteve associada positivamente à afetividade e aceitação das mães e negativamente com a rejeição e punição maternas. Para os autores, esses achados indicam que a inibição comportamental provavelmente apresenta significados adaptativos distintos nas diferentes culturas.

A literatura anglo-saxônica revela certa consistência no que se refere às relações existentes entre práticas educativas punitivas ou coercitivas e alguns tipos de problemas de comportamento, especialmente os problemas de externalização. Entretanto, as investigações de Deater-Deckard e col. (1996) e de Chen e col. (1998), envolvendo crianças chinesas, americanas de origem européia e afro-americanas não revelaram associações entre práticas educativas coercitivas e problemas de comportamento. Entre os estudos brasileiros publicados, não foi encontrado nenhum que examinasse a relação entre práticas educativas e problemas de comportamento

Nesse sentido, o objetivo do presente estudo foi investigar as diferenças entre as práticas educativas relatadas por mães de crianças com problemas de comportamento envolvendo externalização (grupo clínico) e mães de crianças sem problemas de comportamento (grupo nãoclínico). Com base nos achados mais freqüentes relatados na literatura, a expectativa inicial foi de que as mães do grupo clínico, comparadas às mães do grupo não-clínico, relatassem com mais freqüência práticas coercitivas. Além disso, esperou-se que as mães do grupo não-clínico, comparadas às mães do grupo clínico, referissem com maior freqüência o uso de práticas indutivas envolvendo explicações.

\section{Método}

\section{Participantes}

Participaram do estudo 30 díades mãe-criança, de nível sócio-econômico baixo e médio-baixo (renda familiar média de 2,77 salários mínimos, $d p=2,01)$. As crianças eram de ambos os sexos (16 meninas e 14 
meninos) e tinham idade média de 5,8 anos ( $d p=3,14$ meses). As mães tinham idade média de 33,2 anos $(d p=4,99)$.

Os participantes foram recrutados a partir de uma amostra de 634 crianças que faziam parte do Estudo Longitudinal das Crianças Nascidas em Pelotas, RS, Brasil, iniciado em 1993. A história do estudo e da amostra já foi descrita por Victora e colaboradores (1996). Na Fase I do estudo, todas as mães dos 5304 recém-nascidos nos hospitais daquela cidade em 1993, que residiam no perímetro urbano, foram recrutadas ainda no hospital. Durante o primeiro ano de vida da criança, sub-amostras de bebês aleatoriamente escolhidos foram examinadas no primeiro, terceiro, sexto e décimo-segundo mês de vida, com relação a diversos aspectos do desenvolvimento infantil, particularmente quanto ao crescimento físico. Na Fase II, quando as crianças estavam com cerca de quatro anos, foram visitadas 1273 crianças. Aproximadamente metade dessa sub-amostra $(n=634)$ foi selecionada aleatoriamente para se investigar os problemas de comportamento da criança utilizando-se o Child Behavior Checklist (CBCL - Inventário de Comportamentos da Infância e Adolescência, Achenbach, 1991) e o QI da criança através do Wechsler Preschool Intelligence Scale (WPPSI - Test de Inteligencia para Preescolares, Wechsler, 1991).

Os critérios utilizados para a inclusão das díades na presente amostra foram os seguintes: a) idade gestacional: a criança deveria ter nascido a termo; b) ausência de problemas de saúde na criança; c) idade das mães entre 21 e 45 anos; d) renda familiar menor ou igual a 6 salários mínimos; e) QI da criança superior a 70; e, f) pontuação da criança no CBCL.

Tanto na versão original do CBCL (Achenbach, 1991) como na versão brasileira do instrumento (Bordin, Mari \& Caeiro, 1995), crianças com escores acima de 63 pontos são classificadas na categoria clínica; entre 60 e 63, na categoria limítrofe, e crianças com escores abaixo de 60 pontos ficam na categoria não-clínica. No presente estudo, as crianças do grupo clínico deveriam ter escores totais acima de 60 pontos, que as classificavam nas categorias limítrofe ou clínica, e escores na escala de problemas de externalização acima de 63 pontos, que as classificavam na categoria clínica. As crianças do grupo não-clínico deveriam apresentar escores totais abaixo de 55 pontos, e escores na escala de problemas de externalização também abaixo de 55 pontos, que as classificavam na categoria não-clínica nas duas escalas. Foram utilizados pontos de corte inferiores àqueles que delimitam a categoria não-clínica (abaixo de 60 pontos), visando acentuar as diferenças entre os grupos.

Com base nestes critérios, a amostra inicial de 634 crianças foi reduzida para 35 crianças das quais 13 constituíram o grupo clínico e 22, o grupo não-clínico. Após a localização e contato com as famílias, foi marcada uma visita domiciliar. Nesta ocasião, realizou-se uma nova aplicação do CBCL visando a excluir crianças cujos escores não fossem similares aos obtidos na primeira aplicação deste instrumento, seis meses antes. Os índices de correlação entre as duas aplicações do CBCL foram de $0,908(\phi<0,0001)$ para os escores totais e $0,918(p<$ $0,0001)$ para os escores de problemas de externalização. Contudo, cinco crianças classificadas na categoria clínica (com problemas de comportamento), na primeira aplicação não obtiveram os mesmos escores, e por isso foram excluídas do presente estudo. Restaram 13 crianças no grupo clínico e 17 no grupo não clínico, cujas características demográficas encontram-se na Tabela 1.

No grupo clínico, as crianças obtiveram uma pontuação média de 65,08 pontos $(d p=4,96)$ no escore total de problemas de comportamento e 67,85 pontos $(d p=5,26)$ no escore de problemas de externalização. No grupo não-clínico, a média da pontuação no escore total de problemas de comportamento foi de 39,71 $(d p=6,56)$ e de 41,82 $(d p=6,58)$ no escore de problemas de externalização.

\section{Delineamento e Procedimento}

Foi utilizado um delineamento de grupos contrastantes (Nachmias \& Nachmias, 1996) comparando as práticas educativas das mães dos grupos clínico e não-clínico. As díades foram visitadas em suas residências e convidadas a participar da coleta de dados. As mães que concordaram em participar responderam inicialmente a uma ficha de dados demográficos e à Entrevista sobre práticas educativas maternas. Em seguida foi realizada a Observação da interação da díade, que não será analisada neste artigo e, por fim, as mães responderam ao Inventário de Comportamentos da Infância e Adolescência - CBCL.

\section{Instrumentos}

\section{Entrevista sobre Práticas Educativas Maternas}

Foi utilizada uma entrevista estruturada com questões abertas para a investigação das práticas educativas utilizadas pelas mães na regulação do comportamento dos filhos, baseada em Hart e colaboradores (1990) e Piccinini, Maggi e Carro (1993). A primeira parte da entrevista consistia de situações espontâneas relatadas pela mãe em que ela considerasse difícil lidar com seu filho. $\mathrm{Na}$ segunda parte, eram apresentadas seis situações que normalmente ocorrem no cotidiano, envolvendo comportamentos inadequados ou desobediência da criança, a saber: a) a criança recusa-se a almoçar; b) a criança danifica um objeto; c) a criança insiste em vestir 
Tabela 1. Características Demográficas dos Participantes

\begin{tabular}{|c|c|c|c|c|}
\hline & $\begin{array}{l}\text { Grupo Clínico } \\
(n=13)\end{array}$ & $\begin{array}{c}\text { Grupo Não-Clínico } \\
(n=17)\end{array}$ & & ns \\
\hline \multicolumn{5}{|l|}{ Sexo da criança } \\
\hline Masculino & $5(38,5 \%)$ & $9(52,9 \%)$ & $x 2=0,62$ & 0,43 \\
\hline Feminino & $8(61,5 \%)$ & $8(47,1 \%)$ & & \\
\hline \multicolumn{5}{|l|}{ Idade da criança (meses) } \\
\hline$m$ & 70,62 & 68,59 & $F=3,32$ & 0,07 \\
\hline$\not p$ & 2,43 & 3,39 & & \\
\hline \multicolumn{5}{|l|}{ QI da criança } \\
\hline$m$ & 88,08 & 91,76 & $F=0,64$ & 0,42 \\
\hline$d p$ & 13,36 & 11,75 & & \\
\hline \multicolumn{5}{|l|}{ Número de irmãos } \\
\hline$m$ & 2,08 & 1,88 & $F=0,18$ & 0,67 \\
\hline$d p$ & 1,61 & 0,86 & & \\
\hline \multicolumn{5}{|c|}{ Ingresso na pré-escola ou primeira série } \\
\hline Freqüenta (pré-esc. $/ 1^{2}$ série) & $11(85 \%)$ & $8(47 \%)$ & $x 2=0,34$ & 0,06 \\
\hline Não freqüenta & $2(15 \%)$ & $9(53 \%)$ & & \\
\hline \multicolumn{5}{|l|}{ Idade da mãe (anos) } \\
\hline$m$ & 32,62 & 33,65 & $F=0,30$ & 0,58 \\
\hline$d p$ & 4,79 & 5,24 & & \\
\hline \multicolumn{5}{|l|}{ Escolaridade da mãe (anos) } \\
\hline$m$ & 4,62 & 7,12 & $F=5,79$ & 0,02 \\
\hline$\not p$ & 3,01 & 2,67 & & \\
\hline \multicolumn{5}{|l|}{ Ocupação da mãe } \\
\hline Não trabalha & $11(85 \%)$ & $11(65 \%)$ & $x 2=0,49$ & 0,22 \\
\hline Trabalha & $2(15 \%)$ & $6(35 \%)$ & & \\
\hline \multicolumn{5}{|l|}{ Presença do pai } \\
\hline Reside com a criança & $7(54 \%)$ & $12(71 \%)$ & $x 2=0,88$ & 0,34 \\
\hline Não reside com a criança & $6(44 \%)$ & $5(29 \%)$ & & \\
\hline \multicolumn{5}{|c|}{ Renda Familiar (salários mínimos) } \\
\hline$m$ & 2,26 & 3,16 & $F=1,50$ & 0,23 \\
\hline$d p$ & 1,97 & 2,02 & & \\
\hline
\end{tabular}

roupa nova para brincar na rua; d) a criança recusa-se a dormir à noite; e) a criança agride outra criança; e, f) a criança fala palavrões ou ofende outra pessoa. Em ambas as partes da entrevista, após o relato de cada situação, eram investigadas as práticas educativas utilizadas pelas mães. As entrevistas foram gravadas em audiotape e posteriormente transcritas para análise.

Psicologia: Reflexão e Crítica, 2001, 14(3), pp. 449-460
Inventário de Comportamentos da Infância e Adolescência CBCL (Achenbach, 1991)

Este instrumento foi utilizado para se avaliar os problemas de comportamento das crianças. É um questionário que avalia competência social e problemas de comportamento em crianças e adolescentes de quatro a 18 anos, a partir de informações fornecidas pelos pais. $\mathrm{O}$ autor recomenda pontos de corte que determinam as categorias não-clínica, limítrofe e clínica nas escalas de problemas de internalização e externalização (abaixo de 
60 pontos: categoria não-clínica; de 60 a 63 pontos: categoria limítrofe; acima de 63 pontos: categoria clínica) e na escala total (abaixo de 60 pontos: categoria nãoclínica; de 60 a 63 pontos: categoria limítrofe; acima de 63 pontos: categoria clínica). O CBCL foi traduzido para o português e validado por Bordin e colaboradores (1995). Nesta versão do instrumento foram mantidos os mesmos pontos de corte sugeridos por Achenbach no instrumento original.

\section{Resultados}

Análise de conteúdo (Bardin, 1977/1979) foi utilizada para se classificar as práticas educativas maternas relatadas pelas mães, tanto para as situações espontâneas como para as situações estruturadas. Baseada em Hoffman $(1975,1991)$, a análise revelou onze categorias de práticas educativas. Dez delas foram agrupadas em dois grandes grupos: a) Práticas Indutivas: 1) negociação/troca; 2) explicação apontando conseqüências; 3) explicação baseada em convenções; 4) mudança nos hábitos da criança; 5) comando verbal não-coercitivo; e, b) Práticas Coercitivas: 6) punição verbal; 7) ameaça de punição; 8) privação/castigo; 9) coação física; 10) punição física. A décima primeira categoria foi denominada não interferência e não foi classificada nem como prática indutiva, nem como prática coercitiva. As definições das categorias são apresentadas no Anexo A. A classificação das 452 práticas educativas relatadas pelas mães nas duas partes da entrevista foi realizada por dois codificadores que tiveram treinamento extensivo $(20$ horas) e que desconheciam o grupo a que cada díade pertencia. O índice de fidedignidade entre os codificadores foi calculado utilizando-se o coeficiente Kappa em uma amostra de $30 \%$ das entrevistas, e atingiu o valor de 0,87 .

\section{Práticas Educativas Maternas nas Situações Estruturadas}

A partir da análise de conteúdo das respostas das mães às seis situações estruturadas, foram identificadas 336 práticas educativas das quais 54\% (180) foram relatadas pelo grupo não-clínico e 46\% (156) pelo grupo clínico. A Figura 1 ilustra a distribuição de porcentagem de práticas educativas nas situações estruturadas em cada um dos grupos.

Examinando-se os percentuais totais das práticas educativas em cada grupo, constata-se que as seis categorias classificadas como práticas indutivas foram mais freqüentes no grupo não-clínico $(55 \%)$ do que no grupo clínico $(33 \%)$. Em relação às cinco categorias classificadas como de práticas coercitivas, os resultados mostram que

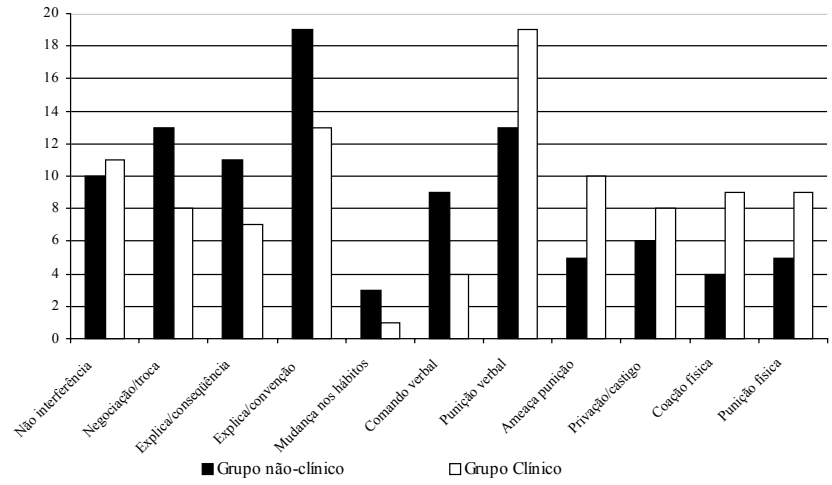

Figura 1. Percentuais de respostas dos grupos clínico e não clínico em cada uma das categorias de práticas educativas nas seis situações estruturadas

elas foram mais mencionadas pelo grupo clínico (55\%) do que pelo não-clínico (33\%). A análise com quiquadrado mostrou que esta diferença encontrada entre os grupos foi significativa $\left(x^{2}=10,02, g l=1, p<0,001\right)$.

Com relação às categorias que compõem as práticas indutivas, os resultados apresentados na Figura 1 mostram que todas foram mais mencionadas pelo grupo nãoclínico do que pelo clínico. As diferenças mais expressivas entre os dois grupos foram constatadas nas categorias explicação baseada em convenção (não-clínico: 19\%; clínico: 13\%), negociação/troca (não-clínico: 13\%; clínico: $8 \%$ ) e comando verbal não-coercitivo (não-clínico: 9\%; clínico: 4\%). Quanto às categorias que compõem as práticas coercitivas, os resultados mostram que todas elas foram mais mencionadas pelas mães do grupo clínico, do que pelas mães do grupo não-clínico (Figura 1). Destacam-se em particular as diferenças entre os dois grupos nas categorias: punição verbal (não-clínico:13\%; clínico: 19\%); ameaça de punição (não-clínico: 5\%; clínico: 10\%), coação física (não-clínico: 4\% e clínico: 9\%), e, punição física (não-clínico: 5\%; clínico: 9\%). Por fim, em relação à categoria não interferência, não houve diferença entre os grupos (não-clínico: 10\%; clínico: 11\%).

Com o objetivo de avaliar eventuais diferenças na tendência para utilizar práticas indutivas ou coercitivas, independentemente das situações, Análise de Variância foi realizada nos dados sobre a incidência média das freqüências de cada prática educativa. A Tabela 2 apresenta a incidência média, desvio-padrão, valor de $F$ e nível de significância do total de práticas educativas mencionadas pelas mães. As variáveis demográficas idade da criança, ingresso da criança na pré-escola ou primeira série e escolaridade da mãe foram incluídas como covariantes, nesta análise, devido às diferenças verificadas entre os dois grupos quanto a esses fatores.

Os resultados revelaram diferença significativa na média total de práticas coercitivas mencionadas pelas mães 
Tabela 2. Média, Desvio-padrão, Valores de F e Nível de Significância do Total de Práticas Educativas nas Situações Estruturadas

\begin{tabular}{lcccc}
\hline & $\begin{array}{c}\text { Grupo não-clínico } \\
\text { Média }(d p)\end{array}$ & $\begin{array}{c}\text { Grupo Clínico } \\
\text { Média }(d p)\end{array}$ & $F$ & $n s$ \\
\hline $\begin{array}{l}\text { Não interferência } \\
\text { Práticas Educativas Indutivas }\end{array}$ & $1,06(0,83)$ & $1,46(1,66)$ & 0,82 & 0,37 \\
$\begin{array}{l}\text { Negociação/Troca } \\
\text { Explicação/conseqüência }\end{array}$ & $1,29(1,10)$ & $1,00(0,71)$ & 0,43 & 0,51 \\
$\begin{array}{l}\text { Explicação/convenção } \\
\text { Muda os hábitos da criança }\end{array}$ & $1,18(1,19)$ & $0,85(0,90)$ & 0,02 & 0,87 \\
Comando verbal não-coercitivo & $0,06(1,03)$ & $1,69(1,38)$ & 1,83 & 0,18 \\
Práticas Educativas Coercitivas & $0,94(0,59)$ & $0,15(0,38)$ & 0,74 & 0,39 \\
Punição verbal & $1,35(1,00)$ & $0,46(0,66)$ & 1,53 & 0,22 \\
Ameaça de punição & $1,59(0,87)$ & $2,15(1,21)$ & 2,14 & 0,15 \\
Privação/Castigo & $0,65(0,86)$ & $1,15(0,69)$ & 2,16 & 0,15 \\
Coação física & $0,47(0,62)$ & $1,00(0,82)$ & 2,21 & 0,15 \\
Punição física & $0,59(0,87)$ & $1,08(0,86)$ & 3,78 & 0,06 \\
\hline Total de práticas indutivas & $5,76(2,61)$ & $4,15(2,15)$ & 1,62 & 0,21 \\
Total de práticas coercitivas & $3,65(2,18)$ & $6,46(2,26)$ & 8,43 & 0,13 \\
Total geral & $9,41(2,27)$ & $10,62(3,12)$ & 1,10 & 0,008 \\
& & & & 0,30 \\
\hline
\end{tabular}

$g l=1,25$

nos dois grupos $(p<0,008)$. No geral o grupo clínico apresentou uma incidência média maior de práticas coercitivas do que o grupo não-clínico ( $m=6,46$ e $m=3,65$, respectivamente). Tendência oposta, mas não significante $(p<0,13)$ ocorreu no total de práticas indutivas (grupo não-clínico: $m=5,76$; grupo clínico: $m=4,15)$. Em nenhuma destas análises houve efeito significativo para as covariantes.

Com relação às categorias que compõem as práticas indutivas e as práticas coercitivas, os resultados não mostraram diferenças significativas. Apenas uma diferença marginalmente significativa apareceu para a categoria coação física $(p<0,06)$. As mães do grupo clínico relataram de modo geral mais coação física do que as do grupo não-clínico. Estas diferenças apoiam parcialmente a expectativa inicial de que as mães do grupo clínico utilizariam mais práticas coercitivas do que indutivas.

\section{Práticas Educativas Maternas nas Situações Espontâneas}

Nesta seção são examinadas as práticas educativas mencionadas nas situações espontâneas. Tais situações foram referidas pelas próprias mães como ocasiões do cotidiano em que era difícil lidar com a criança. Antes de se examinar as estratégias relatadas pelas mães para as situações espontâneas, procedeu-se a uma análise de conteúdo para classificação destas situações (Bardin, 1977/ 1979). As 68 situações espontâneas relatadas pelas mães

Psicologia: Reflexão e Crítica, 2001, 14(3), pp. 449-460 na primeira parte da entrevista (situações espontâneas) foram inicialmente classificadas em sete tipos: Situação 1: desobedecer/teimar/fazer birra; Situação 2: agir de maneira infantilizada/dependente; Situação 3: agredir; Situação 4: fazer travessuras/artes; Situação 5: fazer coisas perigosas; Situação 6: comer mal ou devagar; Situação 7: outras situações. Este último tipo de situação não foi utilizado para a análise de práticas educativas maternas, descrita abaixo, porque as situações classificadas nesta categoria não puderam ser agrupadas de acordo com algum aspecto em comum, como as demais. Dois codificadores classificaram independentemente as 68 situações relatadas pelas mães nestas categorias. $\mathrm{O}$ índice de fidedignidade entre os codificadores foi calculado por meio do coeficiente Kappa, em uma amostra de 30\% das entrevistas e atingiu o valor de 0,88 .

Com o objetivo de examinar eventuais diferenças entre os grupos na freqüência com que mencionaram espontaneamente cada tipo de situação, Análise de Variância foi utilizada na incidência média de situações por grupo. Foram incluídas como covariantes as variáveis idade da criança, ingresso na pré-escola ou primeira série e escolaridade da mãe. A Tabela 3 apresenta a incidência média, desvio-padrão, valor de $F$ e nível de significância dos tipos de situações espontâneas relatadas pelos dois grupos.

Os resultados mostraram uma diferença significativa apenas para a situação agredir $(p<0,03)$ indicando que as 
Tabela 3. Média, Desvio-padrão, Valores de Fe Nível de Significância dos Tipos de Situações Espontâneas

\begin{tabular}{lcllc}
\hline & $\begin{array}{c}\text { Não-clínico } \\
\text { Média }(d p)\end{array}$ & $\begin{array}{l}\text { Clínico } \\
\text { Média }(d p)\end{array}$ & $F$ & ns \\
\hline Desobedecer/ Teimar/ Fazer birra & $0,41(0,71)$ & $1,00(0,91)$ & 2,01 & 0,16 \\
Agir de maneira infantilizada/dependente & $0,29(0,59)$ & $0,54(0,88)$ & 0,33 & 0,56 \\
Agredir & $0,06(0,24)$ & $0,54(0,66)$ & 4,80 & 0,03 \\
Fazer travessuras/artes & $0,41(0,62)$ & $0,15(0,38)$ & 0,17 & 0,68 \\
Fazer coisas perigosas & $0,29(0,47)$ & $0,23(0,60)$ & 0,001 & 0,96 \\
Comer mal ou devagar & $0,24(0,44)$ & $0,15(0,38)$ & 0,38 & 0,53 \\
Outras & $0,06(0,24)$ & $0,15(0,38)$ & 0,36 & 0,55 \\
Total & $1,76(1,35)$ & $2,92(1,98)$ & 2,38 & 0,13 \\
\hline
\end{tabular}

$g l=1,25$

mães do grupo clínico relataram em média mais situações deste tipo do que as mães do grupo não-clínico. Não houve efeito significativo para as covariantes. Esse resultado corrobora os dados do CBCL, cujos escores de externalização foram maiores nas crianças do grupo clínico. Nas demais situações, não houve diferenças significativas entre os grupos.

A análise de conteúdo das práticas educativas maternas mencionadas para as situações espontâneas indicou um total de 116 práticas, das quais $45 \%$ (52) foram relatadas pelo grupo não-clínico e 55\% (64) pelo grupo clínico. A Figura 2 ilustra a distribuição de porcentagem de práticas educativas independentemente das situações espontâneas, em cada um dos dois grupos.

Examinando-se os percentuais totais das práticas educativas em cada grupo, constata-se que as práticas

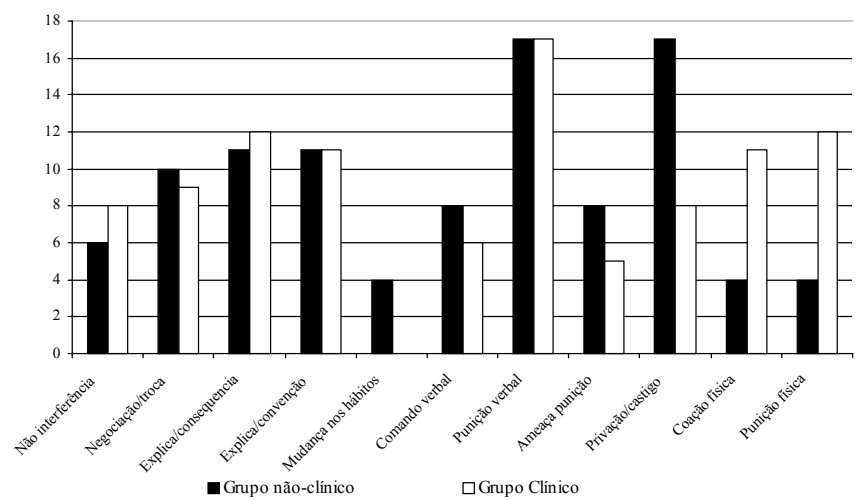

Figura 2. Percentuais de respostas dos grupos clínico e não clínico em cada uma das categorias de práticas educativas nas seis situações espontâneas.

indutivas foram mais freqüentes no grupo não-clínico (44\%) do que no grupo clínico (37\%). Em relação às práticas coercitivas, os resultados mostram que elas foram mencionadas com freqüências semelhantes no grupo clínico (53\%) e no não-clínico (50\%). A análise com qui-quadrado não revelou diferença significativa entre os grupos $(x 2=$ $0,40, g=1, p<0,53)$ no relato de práticas indutivas e coercitivas.
Com relação às cinco categorias que compõem as práticas indutivas e às cinco que compõem as práticas coercitivas, os resultados mostram, de modo geral, uma baixa freqüência de respostas em cada categoria, além de poucas diferenças entre os grupos, à exceção da categoria mudança nos hábitos da criança que foi mencionada somente pelo grupo não-clínico (4\%). Embora não tenham sido encontradas diferenças estatísticas significativas, algumas particularidades se sobressaem em relação às categorias que compõem as práticas coercitivas, como por exemplo, nas categorias: privação/castigo (não-clínico:17\%; clínico: 8\%); punição física (não-clínico: 4\%; clínico: $12 \%$ e coação física (não-clínico: $4 \%$ e clínico: $11 \%$ ). Por fim, em relação à categoria não interferência, não houve diferença entre os grupos (não-clínico: $6 \%$; clínico: 8\%).

Com o objetivo de avaliar eventuais diferenças na tendência para utilizar práticas indutivas ou coercitivas, independentemente das situações, análise de variância foi realizada nos dados sobre a incidência média de cada prática educativa, com idade da criança, ingresso da criança na pré-escola ou primeira série e escolaridade da mãe como covariantes. A Tabela 4 apresenta a incidência média, desvio-padrão, valor de $F$ e nível de significância do total de práticas educativas.

Os resultados não revelaram diferenças significativas no uso de práticas coercitivas e práticas indutivas entre os dois grupos. Por outro lado, a análise das categorias que compõem as práticas coercitivas revelou uma diferença significativa entre os grupos na categoria punição física $(p<0,04)$, mostrando que o grupo clínico apresentou uma incidência média maior do que o grupo não-clínico. Não houve efeito significativo para as covariantes. Com relação às categorias que compõem as práticas indutivas, os resultados mostraram uma diferença significativa na categoria mudança nos hábitos da criança $(p<0,001)$ indicando que o grupo não-clínico apresentou uma incidência média maior do que o grupo clínico, que 
Tabela 4. Média, Desvio-padrão, Valores de F e Nível de Significância do Total de Práticas Educativas nas Situações Espontâneas

\begin{tabular}{lcccc}
\hline & $\begin{array}{c}\text { Grupo não-clínico } \\
\text { Média (dp) }\end{array}$ & $\begin{array}{c}\text { Grupo clínico } \\
\text { Média (dp) }\end{array}$ & $F$ & $n s$ \\
\hline $\begin{array}{l}\text { Não interferência } \\
\text { Práticas Educativas Indutivas }\end{array}$ & $0,21(0,43)$ & $0,38(0,65)$ & 0,09 & 0,75 \\
$\begin{array}{l}\text { Negociação/Troca } \\
\text { Explicação/conseqüência }\end{array}$ & $0,36(0,50)$ & $0,46(0,78)$ & 0,06 & 0,79 \\
$\begin{array}{l}\text { Explicação/convenção } \\
\text { Muda os hábitos da criança }\end{array}$ & $0,36(0,50)$ & $0,54(0,88)$ & 0,49 & 0,49 \\
Comando verbal não-coercitivo & $0,43(0,51)$ & $0,62(1.19)$ & 0,001 & 0,97 \\
Práticas Educativas Coercitivas & $0,14(0,36)$ & $0,00(0,00)$ & 14,69 & 0,001 \\
Punição verbal & $0,29(0,47)$ & $0,23(0,44)$ & 0,02 & 0,88 \\
Ameaça de punição & $0,64(0,84)$ & $0,77(0,83)$ & 0,42 & 0,52 \\
Privação/Castigo & $0,29(0,47)$ & $0,23(0,44)$ & 0,28 & 0,59 \\
Coação física & $0,64(1,15)$ & $0,38(0,51)$ & 0,05 & 0,82 \\
Punição física & $0,14(0,36)$ & $0,54(0,66)$ & 1,17 & 0,29 \\
\hline Total de práticas indutivas & $0,14(0,36)$ & $0,62(0,65)$ & 4,64 & 0,04 \\
Total de práticas coercitivas & $1,57(1,34)$ & $1,85(1,91)$ & 0,0009 & 0,97 \\
Total geral & $1,86(2,21)$ & $2,54(2,03)$ & 0,77 & 0,38 \\
\hline
\end{tabular}

$g l=1,22$

não mencionou esse tipo de prática. Não houve efeito significativo para as covariantes. Embora estas diferenças não apoiem a expectativa inicial de que as mães do grupo clínico utilizariam mais práticas coercitivas tal como ocorreu na análise das situações estruturadas, a diferença encontrada na categoria punição física ainda indica uma tendência nesta mesma direção.

\section{Discussão}

Os resultados do presente estudo apóiam parcialmente a expectativa inicial de que as mães do grupo clínico, comparadas às do grupo não-clínico, utilizariam práticas coercitivas com maior freqüência. Esperava-se ainda que as mães do grupo não-clínico, comparadas às mães do grupo clínico, referissem com maior freqüência o uso de práticas indutivas envolvendo explicações como prática de regulação do comportamento dos filhos. A análise das práticas educativas maternas mencionadas para as situações estruturadas apóiam estas expectativas. Entretanto, o mesmo não ocorreu na análise das práticas relatadas para as situações espontâneas.

O exame das situações estruturadas revelou que os grupos clínico e não clínico diferiram significativamente quanto ao uso de práticas coercitivas e práticas indutivas. Todas as categorias de práticas coercitivas foram mais referidas pelas mães do grupo clínico, enquanto todas as categorias de práticas indutivas foram mais mencionadas pelas mães do grupo não-clínico. A análise de variância confirmou estas diferenças mostrando que o grupo clínico mencionou um total de práticas coercitivas significativamente maior do que o do grupo não-clínico. Contudo, estes achados não foram confirmados nas situações espontâneas. Independentemente do grupo, as práticas coercitivas predominaram no relato das mães, e não houve diferenças significativas entre os grupos quanto ao uso de práticas indutivas e coercitivas, embora a tendência verificada nas situações estruturadas tenha se mantido.

$\mathrm{Na}$ análise de cada uma das categorias de práticas indutivas e coercitivas, tanto nas situações estruturadas, como nas situações espontâneas, poucas diferenças apareceram. No entanto, em todas as categorias que apresentaram diferenças significativas entre os grupos (coação física, mudança nos hábitos da criança e punição física), a direção deu-se da maneira esperada.

Nesse sentido, é possível afirmar que os resultados do presente estudo confirmaram apenas parcialmente a primeira hipótese, de que as mães do grupo clínico utilizariam mais práticas coercitivas do que as mães do grupo não-clínico. Já a segunda hipótese, de que as mães do grupo não-clínico utilizariam com maior freqüência práticas indutivas envolvendo explicações, recebeu pouco apoio dos resultados obtidos.

Os resultados que apontam para o uso mais freqüente de práticas coercitivas pelas mães do grupo clínico apoiam 
os achados da literatura que indicam que esse tipo de prática estaria relacionado aos problemas de comportamento e, em particular, aos problemas de externalização (Campbell, 1995; Chen e cols.,1998; Dodge e cols., 1994; Hart e cols., 1998; Pettit \& Bates,1989; Rothbaum \& Weisz, 1994).

No presente estudo, dentre as práticas coercitivas mencionadas pelas mães, destacou-se a diferença significativa entre os dois grupos quanto ao uso da punição física, nas situações espontâneas e, uma tendência na mesma direção nas situações estruturadas. $\mathrm{O}$ grupo clínico mencionou o uso de punição física com uma freqüência maior do que o grupo não-clínico. Este dado também apóia os achados referidos na literatura que indicam uma relação entre o uso de punição física e problemas de externalização (Deater-Deckard e cols., 1996; Dodge e cols., 1994; Fox e cols., 1995; Pettit e cols., 1997; Rothbaum \& Weisz, 1994).

A coação física também se destacou como uma prática marginalmente mais utilizada pelo grupo clínico do que pelo grupo não-clínico nas situações estruturadas, e uma tendência na mesma direção nas situações espontâneas. Este tipo de estratégia se caracteriza por obrigar ou forçar fisicamente a criança a comportar-se de determinada forma. Embora a coação física não seja descrita pela literatura como um tipo específico de prática coercitiva, é importante assinalar que esse tipo de prática apareceu com certa freqüência nos relatos das mães do presente estudo. Assim como a punição física, a coação física foi um dos tipos de prática coercitiva mais referido pelas mães do grupo clínico, podendo nesse sentido, também estar associada aos problemas de comportamento.

Alguns estudos têm indicado também que além de não favorecer a aquisição de padrões adequados de comportamento, o uso freqüente de estratégias coercitivas tende a fazer com que crianças se comportem de forma coercitiva com seus pares (Hart e cols., 1998; Hart e cols.,1990; Trickett \& Kuczynski, 1986). No presente estudo, quando solicitadas a mencionar situações espontâneas, as mães do grupo clínico, comparadas com as do grupo não-clínico, relataram significativamente mais episódios em que os filhos eram agressivos com irmãos, pares ou com os próprios pais. Nesse sentido é possível afirmar que o uso mais freqüente de práticas coercitivas pelas mães do grupo clínico poderia também estar associado à agressividade dos filhos em relação a outras pessoas, confirmando assim, outros achados da literatura (Hart e cols., 1998; Hart e cols.,1990; Trickett \& Kuczynski, 1986).
Apesar da ineficácia da punição e outras práticas coercitivas em atingir os objetivos de socialização, a grande maioria dos pais costuma utilizá-las no controle do comportamento dos filhos (Grusec \& Kuczynski, 1980), o que também foi confirmado pelo presente estudo, que revelou que mesmo as mães do grupo nãoclínico referiram práticas coercitivas com uma freqüência maior do que a esperada.

Enquanto os resultados das situações estruturadas trazem evidências que apontam para o uso mais freqüente de práticas coercitivas no grupo clínico, isto não foi corroborado pelos resultados obtidos nas situações espontâneas, embora algumas tendências tenham aparecido na mesma direção, como foi explicitado anteriormente. Isto pode estar relacionado com o fato de que, ao serem solicitadas a relatar situações difíceis de lidar, as mães tenham relatado, de um modo geral, situações mais sérias ou graves. Este fator pode ter contribuído para reduzir eventuais diferenças no uso de práticas educativas entre os grupos, tendo em vista que as mães mencionaram situações bastante sérias (ex.: agredir, fazer coisas perigosas), frente as quais todas tenderiam a reagir de modo semelhante, independentemente das características de comportamento do seu próprio filho. É possível ainda que os instrumentos utilizados e a estrutura de categorias, não tenham sido suficientemente sensíveis para revelar detalhes da dinâmica de interação mãe-criança com problemas de comportamento, nestes dois contextos investigados, o de situações estruturadas e o de situações espontâneas.

Por fim, é importante assinalar o fato de que o presente estudo foi realizado com uma amostra de mães e crianças da cidade de Pelotas. Alguns estudos têm demonstrado que a cultura é um importante mediador do efeito das práticas educativas sobre o comportamento da criança (Baumrind, 1972; Chen e cols., 1998; Darling \& Steinberg, 1993). Nesse sentido o efeito das práticas educativas parentais sobre o comportamento da criança pode variar de acordo com a cultura. Por isso, deve-se considerar que os resultados do presente estudo não são de forma alguma conclusivos ou passíveis de generalização, não só em função das evidências escassas que foram obtidas, mas também em função das particularidades da amostra.

De qualquer modo, acredita-se que os estudos a respeito das relações entre práticas educativas e problemas de comportamento possam contribuir para planejar estratégias de intervenção que possibilitem a prevenção e o tratamento dos problemas de comportamento. 


\section{Referências}

Achenbach, T. M. (1991). Manual for the Child Behavior Checklist/ 4-18 and 1991 profile. Department of Psychiatry. University of Vermont, EUA.

Bardin, L. (1979). Análise de conteúdo (L. A. Reto \& A. Pinheiro, Trads.). São Paulo: Martins Fontes. (Original publicado em 1977).

Baumrind, D. (1972). An exploratory study of socialization effects on black children: Some black-white comparisons. Child Development, 43, 261-267.

Bordin, I. A. S., Mari, J. J. \& Caeiro, M. F. (1995). Validação da versão brasileira do "Child Behavior Checklist" (CBCL) (Inventário de Comportamentos da Infância e Adolescência): Dados preliminares. Revista ABP-APAL, 17, 55-66.

Campbell, S. B. (1995). Behavioral problems in preschool children: A review of recent research. Journal of Child Psychology and Psycbiatry, 36(1), 113-149.

Catania, A. C. (1999). Aprendiragem: Comportamento, linguagem e cognição (D. G. Souza, Trad.). Porto Alegre: Artes Médicas.

Chen, X., Rubin, K. H., Cen, G., Hastings, P. D., Chen, H. \& Stewart, S. L. (1998). Child-rearing attitudes and behavioural inhibition in Chinese and Canadian toddlers: A cross-cultural study. Developmental Psychology, 4, 677-686.

Darling, N. \& Steinberg, L. (1993). Parenting style as context: An integrative model. Psychological Bulletin, 113, 487-496.

Deater-Deckard, K., Bates, J. E., Dodge, K. A. \& Pettit, G. S. (1996). Physical discipline among African-American and European-American mothers: Links to children externalizing behaviors. Developmental Psychology, 32, 1065-1072.

Dodge, K. A., Pettit, G. S. \& Bates, J. E. (1994). Socialization mediators of the relation between socioeconomic status and child conduct problems. Child Development, 65, 649-665.

Fox, R. A., Platz, D. L. \& Bentley, K. S. (1995). Maternal factors related to parenting practices, developmental expectations, and perceptions of child behavior problems. The Journal of Genetic Psychology, 156, 431-441.

Grusec, J. E. \& Kuczynski, L. (1980). Direction of effect in socializ ation: A comparision of the parent's versus the child's behavior as determinants of disciplinary techniques. Developmental Psychology, 16, 1-9.

Grusec, J. E. \& Lytton, H. (1988). Social Development: History, Theory and Research. New York: Springer-Verlag.

Hart, C. H., Ladd, G. W. \& Burleson, B. R. (1990). Expectations of the outcomes of social strategies. Relations with socioeconomic status and maternal disciplinary styles. Cbild Development, 61, 127-137.

Hart, C. H. Nelson, D. A., Robinson, C. C., Olsen, S. F. \& McNeillyChoque, M. K. (1998). Overt and relational aggression in Russian nursery-school-age children: Parenting style and marital linkages. Developmental Psychology, 34, 687-697.
Hoffman, M. L. (1975). Moral internalization, parental power, and the nature of parent-child interaction. Developmental Psychology, 11, 228-239.

Hoffman, M. L. (1991). Commentary. Human Development, 34, 105-110.

Hoffman, M. L. (1994). Discipline and internalization. Developmental Psychology, 30, 26-28.

Mussen, P. H., Conger, J. J., Kagan, J. \& Huston, A. C. (1990). Child development \& personality. New York: Harper \& Row.

Nachmias, C. \& Nachmias, D. (1996). Research methods in the social sciences. London: Arnold.

Newcombe, N. (1999). Desenvolvimento infantil: Abordagem de Mussen (C. Buchweitz, Trad.). Porto Alegre: Artes Médicas. (Original publicado em 1996).

Patterson, G. R. \& Stouthamer-Loeber, M. (1984). The correlation of family management practices and delinquency. Child Development, 55, 1299-1307.

Pettit, G. S. \& Bates, J. E. (1989). Family interaction patterns and children's behavior problems from infancy to 4 years. Developmental Psychology, $25,413-420$.

Pettit, G. S., Bates, J. E. \& Dodge, K. A. (1997). Supportive parenting, ecological context, and children's adjustment: A seven-year longitudinal study. Child Development, 68, 908-923.

Piccinini, C. A., Maggi, A. \& Carro, J. (1993, Julho). Strategies used by mothers of German and Italian descent for regulating their children behavior. Trabalho Apresentado na XXII Biennal Meeting, International Society for the Study of Behavior Development, Recife, Brasil: ISSBD.

Rothbaum, F. \& Weisz, J. R. (1994). Parental care giving and child externalizing behavior in nonclinical samples: a meta-analysis. Psychological Bulletin, 116, 55-74.

Sidman, M. (1995). Coerrção e suas implicações (M. A. Andery \& T. M. Sério, Trads.). Campinas: Editorial Psy II. (Original publicado em 1989).

Skinner, B. F. (1994). Ciência e comportamento bumano (J. C. Todorov \& R. Azzi, Trads.). São Paulo: Martins Fontes. (Original publicado em 1954).

Trickett, P. K. \& Kuczynski, L. (1986). Children's misbehavior and parental discipline strategies in abusive and nonabusive families. Developmental Psychology, 22, 115-123.

Victora, C. G., Barros, F. C., Haltern, R., Menezes, A., Horta, B., Tomasi, E., Weiderpass, E., Cesar, J., Olinto, M., Guimarães, P., Garcia, M. \& Vaughan, J. (1996). Estudo longitudinal da população materno-infantil da região urbana do sul do Brasil, 1993: Aspectos metodológicos e resultados preliminares.Cadernos de Saúde Pública, 30, 34-45.

Wechsler, D. (1991). Test de inteligencia para preescolares (WPPSI). Manual. Buenos Aires: Paidós

Recebido: 16/02/2001

Revisado: 07/05/2001

Aceitoe Final: 21/06/2001

Sobre os autores

Patrícia Alvarenga é psicóloga, Professora do Departamento de Psicologia da Universidade Luterana do Brasil e Mestre em Psicologia do Desenvolvimento pelo Instituto de Psicologia da UFRGS.

Cesar A. Piccinini é Professor do Instituto de Psicologia da Universidade Federal do Rio Grande do Sul e Doutor pela University College, University of London. 


\section{Anexo A}

\section{Definições das categorias de práticas educativas maternas}

0. Não interferência: esta categoria foi utilizada quando a mãe afirmava não interferir de nenhuma forma frente ao comportamento da criança. Ex.: "Eu não faço nada"; "Eu deixo ele botar a roupa."

1. Negociação e troca: esta categoria foi empregada quando a mãe referia algum tipo de negociação com a criança, conversando com ela, prometendo-lhe alguma coisa em troca de obediência ou oferecendo-lhe alguma alternativa. Ex.: "Se tu comer mais um pouco tu pode ver TV"; "Eu tento fazer uma brincadeira, fazer ele fazer outra coisa".

2. Explicação apontando conseqüências: esta categoria foi empregada quando a mãe afirmava utilizar explicações que envolvessem a descrição das implicações do comportamento da criança para ela mesma ou para outras pessoas. Ex.: "Tu tem que comer, tu tem que ficar forte porque agora tu tá no colégio, senão tu não vai aprender nada"; "Tu pode machucar ele".

3. Explicação baseada em convençoes: esta categoria foi utilizada quando a mãe referia utilizar explicações que envolvessem normas ou regras sociais relacionadas ao comportamento da criança. Ex.: "Eu ia falar pra ela que roupa de sair é roupa de sair"; "Não diz isso porque é feio."

4. Mudança nos hábitos da criança: esta categoria foi empregada quando a mãe afirmava fazer algum tipo de alteração na rotina da criança para obter uma modificação de comportamento da mesma. Ex.: "Eu mudei a prática. Agora eu acordo ele às 7 horas da manhã, que aí de noite ele fica com sono"; "Eu não deixo comer doce antes do almoço".

5. Comando verbal não-coercitivo: esta categoria foi utilizada quando a mãe referia dar ordens ou fazer pedidos à criança, indicando o comportamento que deveria ser emitido pela mesma de maneira não aversiva ou coercitiva (punitiva). Ex: "Tá na hora do banbo"; "Come tudinho filho".

6. Punição verbal: esta categoria foi empregada quando a mãe relatava repreender ou xingar a criança, demonstrar desaprovação frente ao seu comportamento, proibir verbalmente a criança de fazer algo ou quando dizia utilizar comandos verbais coercitivos, ou seja, dar ordens ou fazer pedidos indicando o comportamento que deveria ser emitido pela criança, porém de forma coercitiva. Ex.: "Ai que coisa bem horrível falar essa palavra"; "Eu grito com ele: Vai já pro banho". "Tu é uma praga mesmo guria".

7. Ameaça de punição: esta categoria foi empregada quando a mãe referia dizer para a criança que iria puni-la, caso não parasse de se comportar de determinada forma. Ex.: "Se tu bater nele de novo eu vou te dar umas palmadas"; "Tu vai comesar a fazer coisa que não deve; tu vai apanhar".

8. Privação/Castigo: esta categoria foi utilizada quando a mãe referia deixar a criança sem de algo que ela gostasse em função de um comportamento inadequado, ou quando relatava castigar a criança deixando-a sozinha em alguma parte da casa ou sentada no sofá, por exemplo. Ex.: "Mando o amigo para casa e ele fica sem ninguém pra brincar"; "Eu boto ele sentado no sofä"; "Eu encerro no banheiro".

9. Coação física: esta categoria foi empregada quando a mãe referia obrigar ou forçar fisicamente a criança a comportarse de determinada forma. Ex.: "Eu levo ele pro banho à força"; "Eu pego e tiro a roupa dele"; "Às vezes eu tenho que segurar ele".

10. Punição física: esta categoria foi empregada quando a mãe relatava utilizar intervenções físicas que causassem dor na criança. Ex.: "Ah, eu dei umas palmadas"; "Eu pego e dou-lhe pau nas duas"; "Dou uns laçassos"; "Dou uns tapinhas só de tirar $p 0$. 